\title{
Decision Making Behaviour and its Influence on the Socio Economic Performance of Farm Households in H-K Region of Karnataka, India
}

\author{
N. S. Nagesh ${ }^{1 *}$, Amrutha T. Joshi ${ }^{1}$, Jagruti B. Deshmanya ${ }^{1}$, G. M. Hiremath ${ }^{1}$, \\ G. B. Lokesh ${ }^{1}$, D. M. Chandargi ${ }^{2}$ and N. Ananda ${ }^{3}$ \\ ${ }^{I}$ Department of Agricultural Economics, College of Agriculture, UAS, Raichur, India \\ ${ }^{2}$ Department of Agricultural Extension Education, College of Agriculture, \\ UAS, Raichur, India \\ ${ }^{3}$ Department of Agronomy, College of Agriculture, UAS, Raichur, India \\ *Corresponding author
}

\section{A B S T R A C T}

\section{Keywords}

Decision making behaviour, Social performance,

Economic performance, Institutional participation

Article Info

Accepted:

20 August 2019

Available Online:

10 September 2019
Agriculture plays a predominant role in Indian economy and contributes 18 per cent to India's gross domestic product. Farmers have to take series of decisions to make farming a viable enterprise. A study was planned to know the decision making behaviour and its influence on the socio economic performance of farm households. The respondents were chosen from three districts viz. Raichur, Gulbarga and Koppal. Thirty farmers from rainfed situation and thirty farmers from irrigated situation were chosen from each district making a total sample size of 180 . The results revealed that Number of family members, achievement motivation score and decision making behaviour score were found to be significantly influencing the annual agricultural income. As the decision making behaviour score increases by one unit the annual agricultural income increases by Rs 9231.28. Type of risk behaviour was not significant implying that whether farmers were risk loving, risk averse or risk neutral did not influence the annual agricultural income significantly. Irrigated rainfed dummy, number of years of schooling, achievement motivation score, risk orientation score and mass media participation were found to be significantly influencing the institutional participation. Number of family members and decision making behaviour score were found to be significantly influencing the total annual income.

\section{Introduction}

Agriculture is the most important sector of Indian Economy. Indian agriculture sector accounts for 18 per cent of India's gross domestic product (GDP) and provides employment to $50 \%$ of the countries workforce. India is the world's largest producer of pulses, rice, wheat, spices and spice products. India has many areas to choose for business such as dairy, meat, poultry, fisheries and food grains etc. For achieving 
self-sufficiency in food production, farmers play an important role as stakeholder in our country. Hence, farmers role is imperative to increase food production and that could be seen in terms of influencing farmers to accept and adopt new technology to increase their farm income, modernizing the farm through improved farm machinery, developing the farm with irrigation facilities, strengthening post-harvest operations, timely marketing of produce to fetch attractive prices and encouraging savings for investment on farm development, education of children etc.,

Farmers in developing countries are frequently exposed to the uncertainties of weather, prices and disease. Many farmers live on the edge of extreme uncertainty, sometimes falling just below, and sometimes rising just above the threshold of survival. Farmers do not know whether rainfall will be good or bad over a season; they do not know the prices they will receive for produce sold; and they do not know whether their crops will be infected by disease. These risks are not under the control of farmers but some farmers have developed ways of coping and managing them (Kahan, 2008).

Farmers make decisions every day that affect farming operations. Many of the factors that affect the decisions they make cannot be predicted with complete accuracy; this is risk. Farming has become increasingly risky as farmers become more commercial. Farmers need to understand risk and have risk management skills to better anticipate problems and reduce consequences.

Decision-making is the principal activity of management. All decisions have outcomes or consequences. However, in most situations the outcome of a decision cannot be predicted. The more complex the risk, the more difficult it becomes for farmers to make an informed decision. For effective decisions to be taken, farmers need information on many aspects of the farming business. Farmers have to find ways of dealing with risk and protecting themselves from the uncertainties of the future.

Decision theory (or the theory of choice) is the study of the reasoning underlying an agent's choices. Decision theory can be broken into two branches: normative decision theory, which gives advice on how to make the best decisions, given a set of uncertain beliefs and a set of values and descriptive decision theory, which analyzes how existing, possibly irrational agents actually make decisions.

It was planned to conduct a study to know the impact of Decision making behaviour on socio economic performance of farm households in Hyderabad Karnataka region of Karnataka

\section{Materials and Methods}

The study was carried out in the Hyderabad Karnataka region. Raichur, Gulbarga and Koppal districts were randomly selected to represent the Hyderabad-Karnataka region. From each district, two taluks were selected, such that one of them represented the rainfed region and the other represented the irrigated region, based on the net irrigated area. From each of the selected taluks, two Gram panchayats were selected randomly, and from each panchayat a village was selected randomly. Thus, totally 12 villages were selected for the study. From each selected village fifteen farmers were selected using simple random sampling method. Thus, the total sample size constituted of 180 respondents.

\section{Annual agricultural income}

Income obtained from crop production, horticultural crops, livestock and other subsidiary enterprises was considered to arrive 
at annual agricultural income. The respondents were grouped into three categories using mean and standard deviation as measure of check.

\section{Institutional participation}

Institutional participation was measured considering their membership in formal groups, informal groups and technical institutions. One score was awarded for possessing membership in each of the organization. The respondents were grouped into three categories using mean and standard deviation as measure of check.

\section{Total annual income}

Total annual income was quantified considering the agricultural income, income from business, wages, salary and income from migration. The respondents were grouped into three categories using mean and standard deviation as measure of check.

\section{Results and Discussion}

\section{Factors influencing Agricultural Income}

In the first stage regression was run taking annual agriculture income as dependent variable and irrigated rainfed dummy, age, number of years of schooling, number of family members, family type, achievement motivation score, risk orientation score, economic motivation score, decision making behaviour score, type of risk behaviour and mass media participation score as independent variables (Table 1). Number of family members, achievement motivation score and decision making behaviour score were found to be significantly influencing the annual agricultural income. Number of family members had a negative influence while both achievement motivation score and decision making behaviour score had a positive influence on annual agricultural income. For every one additional member in the family, the annual agricultural income decreases by Rs 11018.93. This finding is in line with our apriori expectation that with every additional member in the family, the annual agricultural income decreases because the burden on the fixed amount of money increases. For every one unit increase in the achievement motivation score the annual agricultural income increases by Rs 4809.70. With the increase in the achievement motivation score the farmers ability to take more challenges increases, which in turn increases their annual agricultural income. As the decision making behaviour score increases by one unit the annual agricultural income increases by Rs 9231.28. An improvement in the decision making score implies the ability of the farmer to take appropriate decisions in right time, considering the resource constraints and thus leads to enhancement in agricultural income. The findings that age and education were not significant determinants of agricultural income were not in conformity with Mabeet al., (2010). Type of risk behaviour was not significant implying that whether farmers were risk loving, risk averse or risk neutral did not influence the annual agricultural income significantly.

In this regression, 68.10 per cent of the variation in the dependent variable (annual agricultural income) was explained by the independent variables considered in the model. The R square of 68.10 per cent implies that there exists greater scope for including some more appropriate independent variables in the model.

\section{Factors influencing Institutional participation}

In the first stage regression was run taking institutional participation as dependent variable and irrigated rainfed dummy, age, number of years of schooling, number of 
family members, family type, achievement motivation score, risk orientation score, economic motivation score, decision making behaviour score, type of risk behaviour and mass media participation score as independent variables (Table 2). Irrigated rainfed dummy, number of years of schooling, achievement motivation score, risk orientation score and mass media participation were found to be significantly influencing the institutional participation. Achievement motivation score had a negative influence while all other variables, irrigated rainfed dummy, number of years of schooling, risk orientation score and mass media participation had a positive influence on institutional participation. Irrigated farmers are likely to have higher institutional participation to the tune of 0.67 units in comparison rainfed farmers. The irrigated farmers earn higher income per acre in comparison to rainfed farmers and thus the participation in group activities is also higher among irrigated farmers in comparison to rainfed farmers. As the number of years of schooling increases by one year the institutional participation increases by 0.07 units. This observation is in line with our apriori expectation that with increased education, farmers gain more knowledge and awareness leading to higher institutional participation. As the achievement motivation score increases by one unit, the institutional participation decreases by 0.07 units. As the achievement motivation increases, the farmers become more independent and thus their institutional participation decreases. As the mass media participation score increases by one unit, the institutional participation increases by 0.13 units. Farmers receive latest information from various mass media sources and discuss about them in groups, thereby encouraging institutional participation. As the risk orientation score increases by one unit, the institutional participation increases by 0.16 units. As the farmer face more risk, they tend to mitigate them by participation in group activities, thereby increasing institutional participation.

In this regression, 49.50 per cent of the variation in the dependent variable (Institutional participation) was explained by the independent variables considered in the model. The $\mathrm{R}$ square of 49.50 per cent implies that there exists greater scope for including some more appropriate independent variables in the model.

\section{Factors influencing total annual income}

In the first stage, regression was run taking total annual income as dependent variable and irrigated rainfed dummy, age, number of years of schooling, number of family members, family type, achievement motivation score, risk orientation score, economic motivation score, decision making behaviour score, type of risk behaviour and mass media participation score as independent variables (Table 3).

Number of family members and decision making behaviour score were found to be significantly influencing the total annual income. Number of family members had a negative influence while decision making behaviour score had a positive influence on total annual income. For every one additional member in the family, the total annual income decreases by Rs 6220.25 . This finding is in line with our apriori expectation that with every additional member in the family, the total annual income decreases because the burden on the fixed amount of money increases.

As the decision making behaviour score increases by one unit the total annual income increases by Rs 9528.55. An improvement in the decision making score implies an improvement in the ability of the farmer to take appropriate decisions in right time, leading to enhanced total annual income. 
Table.1 Factors influencing Agricultural Income (Economic performance)

\begin{tabular}{|l|c|c|}
\hline \multirow{2}{*}{ Independent variables } & \multicolumn{2}{|c|}{$\begin{array}{c}\text { Dependent Variable: } \\
\text { Coefficients }\end{array}$} \\
\cline { 2 - 3 } Intercept & $-93319.59^{*}$ & -1.74 \\
\hline Irrigated rainfed dummy (D1) & 14645.01 & 1.22 \\
\hline Age (yrs) & -521.62 & -1.29 \\
\hline No. of years of schooling (yrs) & -795.07 & -0.56 \\
\hline Family type dummy (D2) & 13047.99 & 0.84 \\
\hline Achievement motivation score & $4809.70^{* *}$ & 2.21 \\
\hline Risk orientation score & -9469.33 & -1.42 \\
\hline Economic motivation score & 1644.29 & 0.26 \\
\hline Decision making behaviour score & $9231.28^{* * *}$ & 14.07 \\
\hline Type of risk behaviour (D3) & 22807.69 & 1.18 \\
\hline Type of risk behaviour (D4) & 11143.25 & 0.96 \\
\hline Mass media participation score & 2282.76 & 1.27 \\
\hline R square & & 0.681 \\
\hline Adjusted R square & & \\
\hline
\end{tabular}

Note: $* * *=$ Significant at $1 \%$ level

$* *=$ Significant at $5 \%$ level

$*=$ Significant at $10 \%$ level

Table.2 Factors influencing Institutional Participation (Social performance)

\begin{tabular}{|l|c|c|}
\hline \multirow{2}{*}{ Independent variables } & \multicolumn{2}{|c|}{$\begin{array}{c}\text { Dependent Variable: Institutional Participation } \\
\text { Coefficients }\end{array}$} \\
\cline { 2 - 3 } Intercept & $2.99^{* * *}$ & 3.77 \\
\hline Irrigated rainfed dummy (D1) & $0.67^{* * *}$ & 3.77 \\
\hline Age (yrs) & 0.00 & -0.38 \\
\hline No. of years of schooling (yrs) & $0.07^{* * *}$ & 3.30 \\
\hline No. of family members (No.) & 0.02 & 0.59 \\
\hline Family type dummy (D2) & -0.33 & -1.45 \\
\hline Achievement motivation score & $-0.07^{* *}$ & -2.26 \\
\hline Risk orientation score & $0.16^{*}$ & 1.67 \\
\hline Economic motivation score & -0.03 & -0.32 \\
\hline Type of risk behaviour (D3) & -0.18 & -0.63 \\
\hline Type of risk behaviour (D4) & 0.11 & 0.62 \\
\hline Mass media participation score & $0.13^{* * *}$ & 4.75 \\
\hline Decision making behaviour score & 0.0004 & 0.40 \\
\hline R square & & \\
\hline Adjusted R square & & 0.495 \\
\hline
\end{tabular}

Note: $* * *=$ Significant at $1 \%$ level

$* *=$ Significant at $5 \%$ level

$*=$ Significant at $10 \%$ level 
Table.3 Factors influencing Total Income (Economic performance)

\begin{tabular}{|l|c|c|}
\hline \multirow{2}{*}{ Independent variables } & \multicolumn{2}{|c|}{$\begin{array}{c}\text { Dependent Variable: Total annual income (₹) } \\
\text { Coefficients }\end{array}$} \\
\hline Intercept & -59162.15 & -0.81 \\
\hline Irrigated rainfed dummy (D1) & 15921.72 & 0.97 \\
\hline Age (yrs) & 128.47 & 0.23 \\
\hline No. of years of schooling (yrs) & 2402.94 & 1.24 \\
\hline Family type dummy (D2) & 12228.87 & 0.58 \\
\hline Achievement motivation score & -1201.29 & -0.41 \\
\hline Risk orientation score & -1649.94 & -0.18 \\
\hline Economic motivation score & 5643.84 & 0.64 \\
\hline Type of risk behaviour (D3) & 37536.53 & 1.42 \\
\hline Type of risk behaviour (D4) & 17816.28 & 1.12 \\
\hline Mass media participation score & 2313.90 & 0.94 \\
\hline Decision making behaviour score & $9528.55 * * *$ & 10.63 \\
\hline R square & & 0.569 \\
\hline Adjusted R square & & \\
\hline
\end{tabular}

In this regression, 56.90 per cent of the variation in the dependent variable (total annual income) was explained by the independent variables considered in the model. The R square of 56.90 per cent implies that there exists greater scope for including some more appropriate independent variables in the model.

Decision making behaviour has a greater influence on annual agricultural income, institutional participation and total income of the sample farmers as found in the study results. Hence, the decision making behaviour plays a vital role in the socio-economic performance of farm households in study area.
Therefore, it is important to adopt appropriate strategies for upgradation of decision making behaviour among farm households.

\section{References}

Kahan, D., 2008, Managing risk in farming. Farm management extension guide 3, Food and Agricultural Organization, Rome.

Mabe, L. K., Antwi, M. A. and Oladele, O. I., 2010, Factors influencing farm income in livestock producing communities of North-West Province, South Africa. Livestock Res. Rural Dev., 22(8).

\section{How to cite this article:}

Nagesh, N. S, Amrutha T. Joshi, Jagruti B. Deshmanya, G. M. Hiremath, G. B. Lokesh, D. M. Chandargi and Ananda, N. 2019. Decision Making Behaviour and its Influence on the Socio Economic Performance of Farm Households in H-K Region of Karnataka, India. Int.J.Curr.Microbiol.App.Sci. 8(09): 1756-1761. doi: https://doi.org/10.20546/ijcmas.2019.809.203 